\title{
Effect of forage quality and particle size on voluntary feed intake and chewing activities of oxen
}

\author{
A Susenbeth, KP Aiple, GU Lang, R Mayer \\ Institute of Animal Nutrition, University of Hohenheim, 70593 Stuttgart, Germany
}

\begin{abstract}
Chewing activity is an essential factor in digestion of ruminants. The extent of physical breakdown during eating and ruminating influences the passage of feed particles from the rumen and consequently rumen fill and feed intake (Teller et al, 1993, Livest Prod Sci, $33,215-227)$.
\end{abstract}

Four mature Hinterwälder oxen weighing on average $541 \mathrm{~kg}$ were fed ad libitum successively four different forages supple. mented with a constant amount of $400 \mathrm{~g}$ soybean meal per day : long hay of good "hay, and medium "hay $y_{m}$ " quality, straw in long "straw," and chopped "straw" form. After 3 weeks of adaptation nutrient digestibility was measured by total faces collection ( 8 days) and chewing behaviour was monitored by an selfdeveloped automatic recording system (3-9 days).

As expected dry matter intake significantly declines with increasing NDF content and

decreasing digestibility of organic matter. However total chewing activity per day is similar for all diets. Although there is a trend towards higher values when straw is fed, data do not differ significantly. Therefore forage quality significantly influences chewing behaviour if the values are expressed per $\mathrm{kg}$ DM intake. Time for total chewing per $\mathrm{kg} \mathrm{DM}$ of rations with straw is about twice as high as with hay rations. Chopping reduces the time spent for eating whereas time spent for ruminating is not influenced. The high standard deviations for some parameters indicate a considerable variation among animals in chewing behaviour.

It can be concluded that the animals have a maximum daily capacity of time for total chewing of about 13-15 hours. With decreasing forage quality more time has to be spent for chewing per $\mathrm{kg} \mathrm{DM}$ and hence forage intake is lower. Apart from type of forage this limitation can be partly compensated by reduction of particle size.

$$
\text { hay }_{m}
$$

60.4

$$
48.9
$$

$76.0 \pm 1.3$

$10.1 \mathrm{a} \pm 0.2$

$$
\begin{aligned}
& 413 \pm 75 \\
& 398 \pm 43 \\
& 811 \pm 79
\end{aligned}
$$

ruminating
total chewing

time spent per $\mathrm{kg} D M(\mathrm{~min})$

eating

ruminating

total chewing

$\begin{array}{llc}41.0^{\mathrm{a}} \pm 8.1 & 48.6^{\mathrm{a}} \pm 5.6 & 109.0^{\mathrm{b}} \pm 9.4 \\ 39.5^{\mathrm{a}} \pm 4.2 & 48.6^{\mathrm{a}} \pm 4.6 & 84.8^{\mathrm{b}} \pm 5.7 \\ 80.5^{\mathrm{a}} \pm 9.3 & 97.2^{\mathrm{a}} \pm 8.9 & 193.8^{\mathrm{b}} \pm 4.6\end{array}$

$193.8^{\mathrm{b}} \pm 4.6$
$416 \pm 24$

$834+60$

$97.2^{a} \pm 8.9$

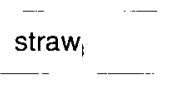

81.1

$53.2 \pm 0.7$

$4.7 \mathrm{c} \pm 0.6$

$511 \pm 110$

$392 \pm 26$

$903 \pm 133$ straw $_{\mathrm{c}}$

81.1

$58.1 \pm 3.4$

$5.4^{\circ} \pm 0.7$

$417 \pm 100$

$442 \pm 40$

$859 \pm 128$

$77.3^{\mathrm{c}} \pm 13.5$

$83.4^{\mathrm{b}} \pm 10.3$

$160.7^{\mathrm{c}} \pm 18.5$

$a, b, c$ Means in same row with unlike letters differ $(P<0.05)$. 